\title{
Design and evaluation of a rabbitry structure at different environments and feeding requirements
}

\author{
John Vincent Nate $^{1}{ }^{*}$, Elijohn Natividad $^{1}$, Jeffrey Lavarias ${ }^{1}$, Romeo Gavino ${ }^{1}$, and Claire \\ Marie Castillo ${ }^{1}$ \\ ${ }^{1}$ Central Luzon State University, Department of Agricultural \& Biosystems Engineering, College of \\ Engineering, Science City of Muñoz, 3120 Nueva Ecija, Philippines
}

\begin{abstract}
This study, focused on a designed cage structure, had a main objective on evaluating the growth performance of caged rabbits at three (3) stocking/spacing reared at three (3) growing conditions. Thirty-six (36) samples of 35-days old Californian White x Local $(\mathrm{CWxL})$ rabbits were reared under three (3) blockings (air-conditioned room, open rabbitry housing and under the trees' shade). Moreover, spacing (A treatment) and feed plan (B treatment) was organized in a $3 \times 4$ Factorial RCBD. $A 2^{\text {nd }}$ factor (feed plan) was used in order to determine the interaction effect of spacing on the rabbits fed with varying levels of nutrition. Results indicated that the treatments and blockings (growing conditions) had significant effects on the Body Weight Gains (BWGs) of rabbits. Similarly, the BWGs were significantly affected by the feed plan but was not affected by spacing and the interaction of these two (2) factors. While no significant effects on BWGs were found out on rabbits placed in small $\left(a_{1}\right)$, medium $\left(a_{2}\right)$ and large (a3) cages, as highest BWGs were seen in the rabbits in medium cages, this cage structure ( $381 \mathrm{~mm}$ x $508 \mathrm{~mm}$ x $406 \mathrm{~mm}$ per rabbit) seemed enough to properly house the rabbits.
\end{abstract}

\section{Introduction}

Rabbit raising industry is one of the emerging agricultural venture in the Philippines. With its introduction to the country as an alternative meat, already supported by the nation's Bureau of Animal Industry, rearing technologies particularly in facilitative environmental design must be given an emphasis.

However, structural and functional requirements designed for the rabbits is not yet available on the Philippine Agricultural Engineering Standards (PAES). In this connection, a prototype cage design was used in this study to evaluate the growth performances of the rabbits under different environments and space requirements. This will serve as one of the basis for further researches in the country, concerning in the design of rabbitry structures as a new livestock industry.

Specifically, the study aimed to describe three (3) growing environments based on its rearing temperature, evaluate the Body Weight Gain (BWG) of the caged rabbits within

*Corresponding author: nate.johnvincent@gmail.com 
different environmental conditions, and also to evaluate the BWG of the caged rabbits under varying space requirements.

\section{Material and methods}

\subsection{Rabbitry structural setup}

The structural and functional components of the rabbitry's prototype cage setup was divided into three (3) components. First, the J-feeders (Figure 1a) that was attached into the cages. This was designed to hold pellets and prevents the spilling of feeds. Second, the water siphoning system (Figure 1b) that was designed to automatically supplied water for rabbits. This was made of a plastic tube and a metal nipple drinker (Figure 1c) that was connected in an elevated water source. Finally, the metal cages that was discussed for the next sub-section.

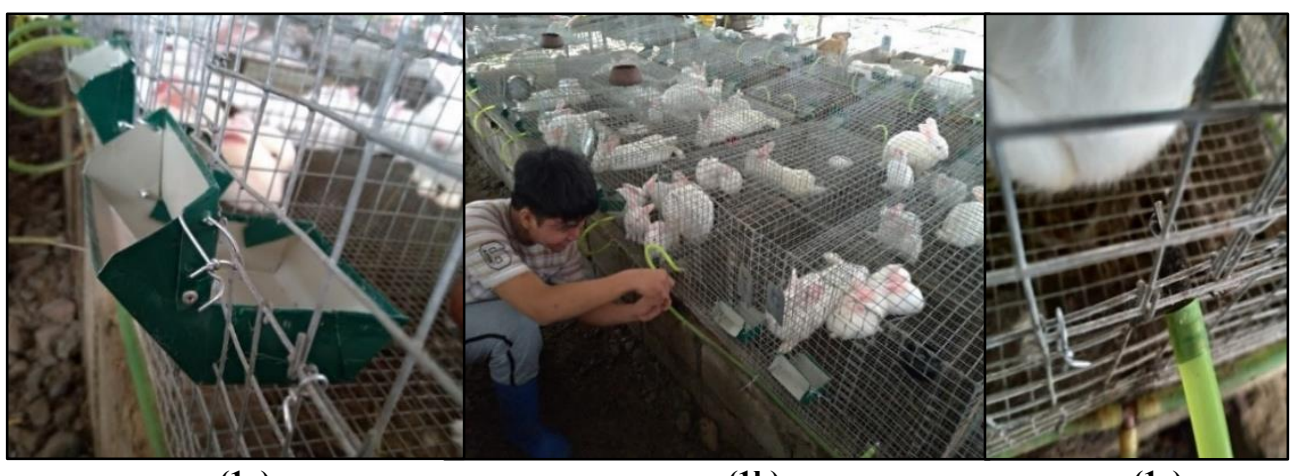

(1a)

(1b)

(1c)

Fig. 1. Rabbitry Structural Setup: 1a (J-feeders); 1b (water siphoning system) \& 1c (nipple drinker).

\subsection{Prototype cage designs}

In order to determine the optimum space requirement or stocking density for rabbits, three (3) types of cages as shown on Figure 2 was fabricated with sizes: small cage (254 mm x 508 $\mathrm{mm}$ x $406 \mathrm{~mm}$ per rabbit); medium cage (381 mm x $508 \mathrm{~mm}$ x $406 \mathrm{~mm}$ per rabbit); and large cage (508 mm x $508 \mathrm{~mm} \times 406 \mathrm{~mm}$ per rabbit). Individual cages was designed following a constant cage height of $406 \mathrm{~mm}$ with constant cage length of $508 \mathrm{~mm}$. Note that only breadth was variable and came up with three (3) area and volume sizes as follows: $A \& V_{\text {small }}=0.129$ $\mathrm{m}^{2} \& 0.052 \mathrm{~m}^{3} ; \mathrm{A} \& \mathrm{~V}_{\text {medium }}=0.194 \mathrm{~m}^{2} \& 0.079 \mathrm{~m}^{3}$; and $\mathrm{A} \& \mathrm{~V}_{\text {large }}=0.258 \mathrm{~m}^{2} \& 0.105 \mathrm{~m}^{3}$.

In terms of percentage differences, medium cages was designed to be $150.39 \%$ (area) and $151.92 \%$ (volume) larger than the small cages. Likewise, large cages was designed to be $200 \%$ (area) and $201.92 \%$ (volume) larger than the small cages. The rabbit cage was made up of $1 / 2$ inch wire mesh of gauge \#16 at the floor. For wall and cage's top, a gauge \#16 with 1 -inch wire mesh was used. Moreover, the cages was elevated at $600 \mathrm{~mm}$ above the ground. 


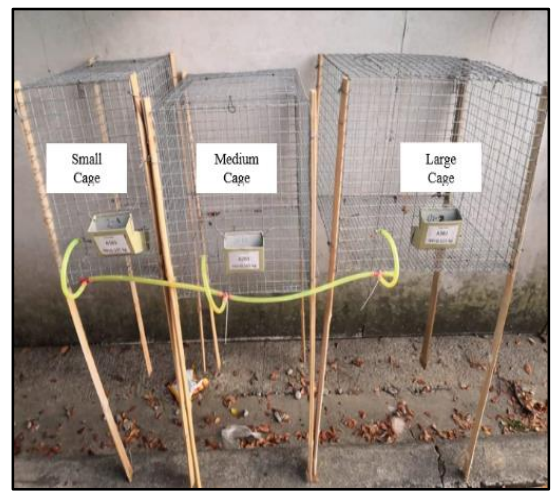

Fig. 2. Three (3) types of space requirement treatments on rabbits.

\subsection{Rabbitry growing environments}

The rabbits were divided and grown into three (3) environments having different temperature ranges. First, an air-conditioned room (Figure 3a) that was fully enclosed and provided with an earth flooring that absorbs rabbits' manure and urine. Second, an open rabbitry housing that was designed in a shed-type housing made of GI sheet roofing and bamboo supports (Figure 3b). Finally, the under the trees' shade, which was an economical environment providing protection against sunlight (Figure 3c).

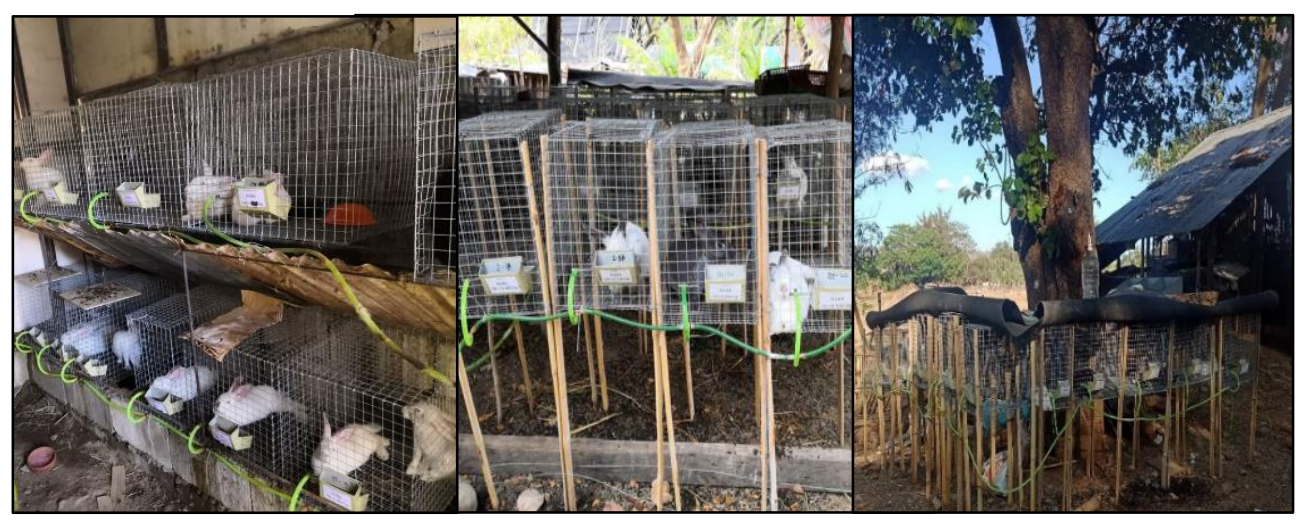

(3a)

(3b)

(3c)

Fig. 3. Rabbitry Growing Environments: $3 a$ (air-conditioned room); $3 b$ (open rabbitry housing) \& $3 c$ (under the trees' shade).

\subsection{Pelleted diet for rabbits}

There were three (3) levels of pelleted diets fed on rabbits including one (1) commercial chicken pellet as the control. The three (3) diets were divided into three (3) levels as follows: low, average and high Crude Protein (CP) and Crude Fiber (CF) levels as shown on Table 1. 
Table 1. Biomass feedstock proportion for the three (3) feed plan treatments.

\begin{tabular}{|c|c|c|c|}
\hline \multirow[b]{2}{*}{ Ingredients } & \multicolumn{3}{|c|}{ Amount ( $\mathrm{g}$ of biomass $x 1 \mathrm{~kg}$ of biofeed ${ }^{-1}$ ) } \\
\hline & $\begin{array}{l}\text { Low CP:CF } \\
\text { Ratio } \\
\text { Biofeed Plan }\end{array}$ & $\begin{array}{c}\text { Average CP:CF } \\
\text { Ratio } \\
\text { Biofeed Plan }\end{array}$ & $\begin{array}{l}\text { High CP:CF } \\
\text { Ratio } \\
\text { Biofeed Plan }\end{array}$ \\
\hline Soybean Meal (Glycine max) & 353.94 & 424.85 & 495.764 \\
\hline Kangkong (Ipomoea aquatica) & 123.08 & 61.57 & 0.054 \\
\hline Malunggay (Moringa oleifera) & 19.33 & 19.43 & 19.522 \\
\hline Napier (Pennisetum purpureum) & 473.65 & 464.15 & 454.66 \\
\hline Molasses & 30.00 & 30.00 & 30.00 \\
\hline Total & 1000.00 & 1000.00 & 1000.00 \\
\hline
\end{tabular}

\subsection{Rabbit samples}

The samples used in the experiment were the 35-days old CWxL rabbits, considering both males and females as samples. Due to the fact that both males and females does not have so much difference in their growth performances (as observed by the local rabbit breeders), it was assumed to not considered the sex as another factor to be applied in the statistical design.

\subsection{Recording and observation on rabbits}

The assessment of the growth performance for the samples were observed within five (5) weeks. The start of rabbit feeding was on its 35th day or 5th week until on its 10 th week. Recording was done weekly at 8:00 AM in the morning using a digital weighing scale.

\subsection{Feeding schedule on rabbits}

Feeding schedule for rabbits was done every 6:00 PM in the evening. The feed consumption was varying at different age such that: $60 \mathrm{~g}\left(1^{\text {st }}\right.$ week $) ; 70 \mathrm{~g}\left(2^{\text {nd }}\right.$ week $)$; and $80 \mathrm{~g}\left(3^{\text {rd }}\right.$ to $5^{\text {th }}$ week). Hence, feeding from the 1 st week to final week of observation varies among each other. Daily feed intake reading was also set on 6:00 PM until 9:00 PM in the evening. Moreover, the samples was having an unlimited water supply from an automatic drinker.

\subsection{Experimental design}

The study was laid out in a two-factorial experiment involving three (3) levels of space requirement or stocking density and four (4) types of feed in a Randomized Complete Block Design (RCBD) having three (3) blockings (i.e., growing conditions) as shown at Table 2.

Table 2. The $3 \times 4$ factorial design for the three (3) levels of spacing and four (4) types of feeds ${ }^{\mathrm{a}}$.

\begin{tabular}{lccc}
\hline \multirow{2}{*}{$\begin{array}{c}\text { Types of Feed Plan } \\
\text { (Factor B) }\end{array}$} & \multicolumn{3}{c}{ Space Requirement or Stocking Density (Factor A) } \\
\cline { 2 - 4 } & Small $\left(\mathrm{a}_{1}\right)$ & Medium $\left(\mathrm{a}_{2}\right)$ & Large $\left(\mathrm{a}_{3}\right)$ \\
\hline Low CP:CF Ratio ( $\left.\mathrm{b}_{1}\right)$ & $\mathrm{a}_{1} \mathrm{~b}_{1}$ & $\mathrm{a}_{2} \mathrm{~b}_{1}$ & $\mathrm{a}_{3} \mathrm{~b}_{1}$ \\
Average CP:CF Ratio $\left(\mathrm{b}_{2}\right)$ & $\mathrm{a}_{1} \mathrm{~b}_{2}$ & $\mathrm{a}_{2} \mathrm{~b}_{2}$ & $\mathrm{a}_{3} \mathrm{~b}_{2}$ \\
High CP:CF Ratio ( $\left.\mathrm{b}_{3}\right)$ & $\mathrm{a}_{1} \mathrm{~b}_{3}$ & $\mathrm{a}_{2} \mathrm{~b}_{3}$ & $\mathrm{a}_{3} \mathrm{~b}_{3}$ \\
Control (b4) & $\mathrm{a}_{1} \mathrm{~b}_{4}$ & $\mathrm{a}_{2} \mathrm{~b}_{4}$ & $\mathrm{a}_{3} \mathrm{~b}_{4}$ \\
\hline
\end{tabular}

Two-way Analysis of Variance (ANOVA) at 1\% and 5\% level of significance was employed and comparison among treatment means was made using Fisher's Least Significant Difference (LSD) Test. 


\subsection{Body weight gain (BWG)}

The BWG (g) of rabbit samples could be computed using Equation 1:

$$
B W G=F W-I W
$$

where: $B W G$ is body weight gain $(\mathrm{g}), I W$ is Initial weight $(\mathrm{g}), F W$ is final weight (g)

\section{Results and discussion}

\subsection{Description of the growing environments}

The environmental conditions in the three (3) growing environments considered as blockings were summarized in Figure 4.

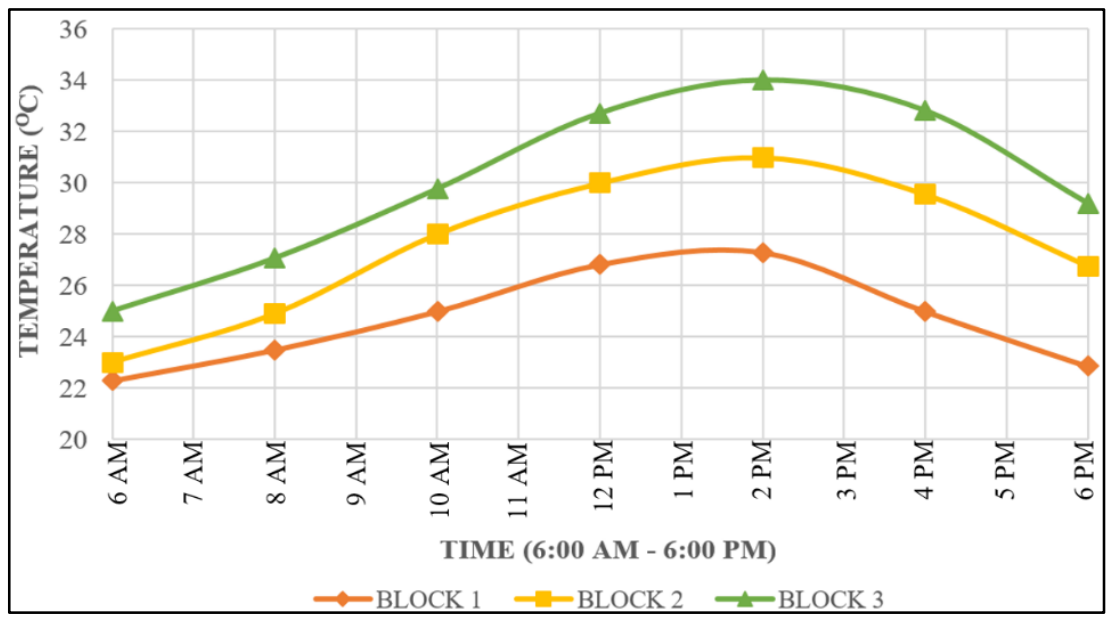

Fig. 4. Average ambient temperature in the growing environments for the duration of experiment.

The three (3) blocks showed a notable differences among each other in terms of ambient temperature trends. The Block I setup, an enclosed room with ACU (Air Conditioning Unit), was found out to had the lowest recorded temperatures. It was followed by the Block II setup, an open rabbitry housing. Likewise, the Block III setup, an under the trees' shade location, was found out to had the highest recorded temperatures.

\subsection{BWGs of the rabbits at different growing conditions}

The various blocks with their corresponding rabbits' mean BWGs was shown on Table 3. It was distinct that the Block I had the lowest temperature (Air Conditioner was set at $17^{\circ} \mathrm{C}$ ) yet produced the lowest BWGs. In this case, other external factors that was not considered in the study dealt an effect in relation with the growth performance of the rabbits.

As for Block I that was installed with exhaust fan in order to provide ventilation in the structure, the ammonia produced from rabbits' waste was not minimized to a safe level (high ammonia concentration in the enclosed room was noticeable due to its strong smell). It was 
noted that exposure to high ammonia concentrations has a strong negative effect on both productive and reproductive traits in the rabbits [1].

Table 3. BWGs under Three (3) Blocks of Varying Environmental Conditions.

\begin{tabular}{lcc}
\hline \multicolumn{1}{c}{ Blocks } & Average Temperature $\left({ }^{\mathbf{0}} \mathbf{C}\right)$ & Mean of BWGs $(\mathbf{g})$ \\
\hline I (Enclosed Room with ACU & 25.21 & 655.5 \\
Setup) & 27.92 & 853.125 \\
II (Open Rabbitry Setup) & 30.47 & 753.75 \\
III (Under Trees' Shade Setup) & \\
\hline
\end{tabular}

The rabbits under the Block II was considered to had the highest BWGs among the three (3) growing conditions. In this case, good air circulation was considered to be the aid that removed the excess ammonia within the open rabbitry. It was also strategically surrounded by trees that was noted as a good practice in designing a rabbitry structure [2].

The rabbits under the Block III was found out to be the $2^{\text {nd }}$ highest in producing BWGs. Similar with the case in Block II, being in an open area, provided good air circulation for ensuring lesser contamination in ammonia. Carbon dioxide $\left(\mathrm{CO}_{2}\right)$, even though not evaluated in the study, could also be lesser due to the trees present in the Block III. This trees provided not only sunlight shed, but also facilitated in photosysnthesis (i.e., $\mathrm{CO}_{2}-\mathrm{O}_{2}$ exchange), considering oxygen as vital component of rabbits for respiration. It was also noted that the average temperature under the Block III $\left(30.47^{\circ} \mathrm{C}\right)$ did not meet the critical temperarure set for rabbits.

Environmental temperatures of $32^{\circ} \mathrm{C}$ and higher is the start of the rabbit's heat stress, leading to production losses [2]. When temperatures of $35^{\circ} \mathrm{C}$ and higher persist, the greatest losses from heat stress may result. However, mortality due to heat stress was still occurred from a sample (i.e., $\mathrm{a}_{2} \mathrm{~b}_{3}$ ) under the Block III.

\subsection{BWGs of the rabbits under varying space requirements and feed plans}

The analysis of variance for Table 4 indicated that the treatments and blocking had significant effects on the BWG of rabbits. Similarly, the BWG was significantly affected by the feed plan diet (Factor B) but was not affected by the space requirement and the interaction of these two (2) factors.

Futhermore, while no significant effects on BWGs were found out on rabbits placed in small $\left(a_{1}\right)$, medium $\left(a_{2}\right)$ and large $\left(a_{3}\right)$ cage, as highest BWGs were seen in the rabbits in medium cages, the medium cages seemed enough to house the rabbits at 70 days old.

Even though control condition produced the highest BWG among the samples (i.e., 1085 g), the control (commercial chicken pellets) were still statistically the same with the formulated feeds at average and high $\mathrm{CP}: \mathrm{CF}$ ratio levels.

Table 4. Spacing (Factor A) and feed plan (Factor B) two -way Table of BWGs (g) Means.

\begin{tabular}{ccccc}
\hline Factor B & \multicolumn{2}{c}{ Factor A (Space Requirement) } & \multirow{2}{*}{ B's Means $^{\mathbf{a}}$} \\
\cline { 2 - 4 } (Feed Plan Diet) & Small Cage & Medium Cage & Large Cage & \\
\hline Low CP:CF Ratio & 555.0 & 497.50 & 550.0 & $534.17^{\mathrm{B}}$ \\
Average CP:CF Ratio & 815.0 & 833.33 & 721.67 & $790.00^{\mathrm{A}}$ \\
High CP:CF Ratio & 637.50 & 900.0 & 887.50 & $808.33^{\mathrm{A}}$ \\
Control & 931.67 & 1085.0 & 722.50 & \\
A's Means & 734.79 & 828.96 & 720.42 & \\
\hline
\end{tabular}

${ }^{a}$ Means not sharing big letter in common differ significantly by Fisher's LSD Test at 5\% level of significance (Biofeed's Main Effect). 
Note that early weaned rabbits about (3) weeks of age must had stocking density about 16 rabbits $\mathrm{x} \mathrm{m}^{-2}$ (1 rabbit within $0.063 \mathrm{~m}^{2}$ ) in group cages [3]. Since the study was using individual cages of stocking densities: 1 rabbit within $0.129 \mathrm{~m}^{2}$ (small cage), 1 rabbit within $0.193 \mathrm{~m}^{2}$ (medium cage) and 1 rabbit within $0.258 \mathrm{~m}^{2}$ (large cage), it was found out that the rabbits in individual cages required larger areas (compared with group cages) in order to have good growth performance (i.e., no negative BWGs). Additional observation was about the behavior of rabbits. The samples were usually lying down on the cage and sometimes stretching out. This indicated that they were in a comfortable state and hence facilitating in gaining more BWGs due to less stressful environment.

\section{Conclusions}

From the analysis of results and data gathered, the following conclusions were formed from this research: (1) air-conditioned room, even though having the lowest temperature, does not favor a good growth performance for the rabbits; (2) there were no significant differences among the cages with a stocking density $(\mathrm{SD})$ of $\mathrm{SD}_{\text {small }}=1$ rabbit $\times 0.129 \mathrm{~m}^{-2} ; \mathrm{SD}_{\text {medium }}=1$ rabbit $\times 0.193 \mathrm{~m}^{-2}$; and $\mathrm{SD}_{\text {large }}=1$ rabbit $\times 0.258 \mathrm{~m}^{-2}$; and (3) medium cage deign $(381 \mathrm{~mm}$ x $508 \mathrm{~mm}$ x $406 \mathrm{~mm}$ per rabbit) produces the highest BWGs among other cage structures.

The following recommendations were also made as a guide for further studies to be conducted: For the control environmental design, some modifications can be employed: (a) installation of insulating materials on the walls of Block I Site (i.e., air-conditioned room) and plastic curtain will reduced the heat entering the enclosed room; consider also better air ventilation to reduce ammonia contamination; and (b) higher ceiling height for the design of the shed-type housing for Block II Site (i.e., open rabbitry housing).

Appreciation and recognition were hereby conveyed by the researchers to the people who shared their valuable time and benevolent effort, in terms of financial and technical support in the completion of this research work.

Wholehearted gratitude to: Philippine Carabao Center (PCC) for their aid in the laboratory analyses of the pretest and main experiment's feed plans; Staffs of the Small Ruminant Center (SRC), for allowing the researchers to use their equipment and for their assistance in the operation of the hammer mill; and Jabez Marketing Cooperative (JMC), for its financial support on this study through lending the researchers an experimental area and essential components in the design and fabrication of the rabbitry structure.

\section{References}

1. J. Sahuquillo, A. Villagrá, V. Blanes, C. Torres, A.G. Torres, Effects of ammonia concentration on reproductive performance in rabbits, in Proceedings of the AgEng 2004, September 2004, Leuven, Belgium (2004)

2. A.M. El-Raffa, Rabbit production in hot climates, in Proceedings of the 8th World Rabbit Congress, 7-10 September 2004, Puebla, Mexico (2004)

3. Z. Matics, Z. Orova, Z. Szendro, W. Bessei, I. Radnai, E. Biró-Németh, M. Gyovai, The free choice of rabbits among identically and differently sized cages, in Proceedings of the 8th World Rabbit Congress, 7-10 September 2004, Puebla, Mexico (2004) 